\title{
Practical Treatment Considerations in the Management of Genitourinary Syndrome of Menopause
}

\author{
Risa Kagan ${ }^{1}$ (1) - Susan Kellogg-Spadt ${ }^{2,3}$. Sharon J. Parish ${ }^{4}$
}

Published online: 26 August 2019

(c) The Author(s) 2019

\begin{abstract}
Genitourinary syndrome of menopause is a condition comprising the atrophic symptoms and signs women may experience in the vulvovaginal and bladder-urethral areas as a result of the loss of sex steroids that occurs with menopause. It is a progressive condition that does not resolve without treatment and can adversely affect a woman's quality of life. For a variety of reasons, many symptomatic women do not seek treatment and, of those who do, many are unhappy with their options. Additionally, many healthcare providers do not actively screen their menopausal patients for the symptoms of genitourinary syndrome of menopause. In this review, we discuss the clinical presentation of genitourinary syndrome of menopause as well as the treatment guidelines recommended by the major societies engaged in women's health. This is followed by a review of available treatment options that includes both hormonal and non-hormonal therapies. We discuss both the systemic and vaginal estrogen products that have been available for decades and remain important treatment options for patients; however, a major intent of the review is to provide information on the newer, non-estrogen pharmacologic treatment options, in particular oral ospemifene and vaginal prasterone. A discussion of adjunctive therapies such as moisturizers, lubricants, physical therapy/dilators, hyaluronic acid, and laser therapy is included. We also address some of the available data on both the patient and healthcare providers perspectives on treatment, including cost, and touch briefly on the topic of treating women with a history of, or at high risk for, breast cancer.
\end{abstract}

\section{Introduction}

Menopause is a normal mid-life event associated with diminished function of the ovaries that results in lower levels of sex steroids. It can also be induced by surgical removal or permanent damage to the ovaries by cancer treatments. The average age of onset of menopause is 51 years. Given current life expectancies, most women can expect to live almost $40 \%$ of their lives after menopause [1]. Regardless of when and how it occurs, women experience menopause differently.

Genitourinary syndrome of menopause (GSM) is a collection of symptoms and signs associated with a decrease in

Risa Kagan

kaganr@sutterhealth.org

1 Department of Obstetrics, Gynecology and Reproductive Sciences, University of California, San Francisco, Affiliated with Sutter East Bay Medical Foundation, Sutter East Bay Medical Group, 2500 Milvia Street, Berkeley, CA 94704, USA

2 Drexel University College of Medicine, Philadelphia, PA, USA

3 Center for Pelvic Medicine, Bryn Mawr, PA, USA

4 Weill Cornell Medical College, New York, NY, USA sex steroids involving changes to the labia majora/minora, clitoris, vestibule/introitus, vagina, urethra, and bladder. It is a chronic, progressive condition that affects up to $50 \%$ of menopausal women and is unlikely to improve without treatment. Genitourinary syndrome of menopause may also include genital dryness, burning, and irritation; sexual symptoms such as lack of lubrication, discomfort, pain, and impaired function; and urinary symptoms of urgency, dysuria, and recurrent urinary tract infections. Women may experience some or all of these signs and symptoms, which should not be better accounted for by another diagnosis in addition to or other than GSM [2]. Genitourinary syndrome of menopause does not include vasomotor symptoms (VMS).

\section{Genitourinary Syndrome of Menopause Clinical Presentation}

Until 2014, GSM was referred to as vulvovaginal atrophy (VVA), atrophic vaginitis, or urogenital atrophy. The change in terminology was made because existing terms were not considered medically accurate. There was no reference to lower urinary tract symptoms such as frequency, urgency, 


\section{Key Points}

Genitourinary syndrome of menopause (GSM) is the accepted term to describe the genitourinary symptoms and signs related to menopause. It does not include vasomotor symptoms.

The percentage of women with confirmed symptoms of GSM is high and expected to increase because of population aging.

Despite the availability of many types of treatments (e.g., systemic and vaginal estrogen, non-hormonal therapies such as ospemifene and prasterone, and numerous adjunctive therapies such as moisturizers, lubricants, and laser therapy), women remain unsatisfied with their choices for a variety of reasons.

More open communication between the patient and healthcare personnel is needed to elicit patient perspectives on their understanding of GSM, objectives for care, and satisfaction and concerns with treatment.

Women with GSM who have, have had, or who are at high risk for breast cancer are particularly underserved.

nocturia, and urinary tract infections. Further, the term "atrophy" carries a negative connotation for most women. In 2014, after hosting a terminology consensus conference, the North American Menopause Society (NAMS) and the International Society for the Study of Women's Sexual Health formally endorsed the term GSM to describe the genitourinary tract symptoms related to menopause. The term is also accepted by the American College of Obstetricians and Gynecologists and is considered medically more accurate and inclusive than prior terms and without negative connotations [2]. Symptomatic VVA is now considered a component of GSM. Throughout the review, we use the terms GSM, VMS, and VVA, where appropriate, to remain consistent with the original language in the clinical studies, literature, and in the actual drug approvals.

The percentage of postmenopausal women with VVA confirmed by examination is between 67 and $98 \%$, whereas the prevalence of patients with symptoms of VVA has been reported to be about 50\% [3]. In the Vaginal Health: Insights, Views and Attitudes survey, $45 \%$ of postmenopausal women reported experiencing vaginal symptoms, but only $4 \%$ were able to identify these symptoms as related to menopause or hormonal changes. Only $32 \%$ sought help from a gynecologist [4]. Reasons given for not speaking with a healthcare professional (HCP) about their symptoms included embarrassment, belief that the symptoms were a normal part of aging and nothing could be done, and belief that the topic was inappropriate to discuss with their physician [1].
Genitourinary syndrome of menopause can lead to genital and urologic complications and higher $\mathrm{pH}$ levels, which encourage the growth of pathogenic bacteria leading to urinary tract infections and vaginitis. Possible secondary genital conditions include labial atrophy, pelvic organ or vaginal vault prolapse, and introital stenosis. Urologic complications can include meatal stenosis, urethral prolapse or atrophy, or urethral polyp and caruncle [5]. Several surveys have detailed the negative effects of GSM on quality of life, emotional wellbeing, sexual functioning and relationships, and body image of menopausal women [6-9]. In the Women's Voices in the Menopause study, $52 \%$ of the participants reported a negative effect from GSM with $40 \%$ noting a negative impact on their sex life. Almost one-third reported that the vaginal symptoms made them "feel old" [1]. In another study of postmenopausal women, GSM symptoms adversely affected sexual interest (59\%), intimacy and relationship with a partner (55\%), mood (42\%), and self-esteem (34\%) [1]. Cumming et al. noted that postmenopausal women tried to hide their symptoms from their partner (61\%), made excuses to avoid intercourse because of their symptoms (42\%), and felt less confident (62\%) [10].

The vaginal microbiota plays an important role in preventing colonization by pathogenic organisms, including sexually transmitted and urinary tract infectious agents, and broadly acts to maintain a women's gynecologic and reproductive health [11]. An environment rich in Lactobacillus species is associated with vaginal health [12], while the loss of Lactobacillus is associated with VVA, vaginal dryness, and gynecologic infections [12]. Women with GSM are more often found to have a bacterial flora that is relatively lower in Lactobacillus [11]. Estrogen not only improves vaginal symptoms, but also allows for re-colonization of the postmenopausal vagina with Lactobacillus [12]. It also contributes to the deposition of glycogen in the vaginal epithelium, which is metabolized by indigenous bacterial communities to produce organic acids needed to protect the genital tract [11].

\section{Treatment Guidelines}

Results from the Women's Health Initiative clinical trials suggesting that the risks of combined estrogen/progestin therapy exceeded the benefits [13] convinced many postmenopausal women to stop using systemic estrogen therapy (ET) [14]. In their 2017 position statement, NAMS suggested that an individual benefit-risk profile that considers formulation, route of administration, and timing of therapy should be created for each woman considering hormone therapy [15]. A review of the literature revealed seven organizations that issued 11 separate sets of guidelines and/or position/consensus statements concerning treatments for GSM-related symptoms in postmenopausal women (Table 1). Three of these provide guidance for the treatment of women at risk for, or with a history of, breast cancer. 
Table 1 Current guidelines

\begin{tabular}{|c|c|c|c|}
\hline Main society/organization & Focus & Type & Year \\
\hline American College of Obstetricians and Gynecologists & Management of menopausal symptoms [16] & Practice bulletin & 2014; reaffirmed 2018 \\
\hline American College of Obstetricians and Gynecologists & $\begin{array}{l}\text { Management of gynecologic issues in women } \\
\text { with breast cancer [17] }\end{array}$ & Practice bulletin & 2012; reaffirmed 2016 \\
\hline American Society of Clinical Oncology ${ }^{a}$ & Sexual problems in people with cancer [18] & Clinical practice guideline & 2017 \\
\hline Endocrine Society ${ }^{\mathrm{b}}$ & Treatment of symptoms of menopause [19] & Clinical practice guideline & 2015 \\
\hline Endocrine Society ${ }^{\mathrm{c}}$ & Androgen therapy in women [20] & Clinical practice guideline & 2014 \\
\hline International Menopause Society & $\begin{array}{l}\text { Women's mid-life health and menopause hor- } \\
\text { mone therapy [21] }\end{array}$ & Recommendations & 2016 \\
\hline $\begin{array}{l}\text { International Society for the Study of Women's } \\
\text { Sexual Health/North American Menopause Society }\end{array}$ & $\begin{array}{l}\text { The role of androgens in the treatment of GSM } \\
\text { [22] }\end{array}$ & Consensus panel review & 2018 \\
\hline National Comprehensive Cancer Network & $\begin{array}{l}\text { Principles of menopause management in female } \\
\text { survivors [23] }\end{array}$ & Clinical practice guideline & 2019 \\
\hline North American Menopause Society & Management of symptomatic VVA [24] & Position statement & 2013 \\
\hline North American Menopause Society & Non-hormonal management of VMS [25] & Position statement & 2015 \\
\hline North American Menopause Society ${ }^{\mathrm{d}}$ & Hormone therapy position statement [15] & Position statement & 2017 \\
\hline $\begin{array}{l}\text { North American Menopause Society/ } \\
\text { International Society for the Study of Women's } \\
\text { Sexual Health }\end{array}$ & $\begin{array}{l}\text { Management of GSM in women with or at high } \\
\text { risk for breast cancer [26] }\end{array}$ & Consensus recommendation & 2018 \\
\hline
\end{tabular}

GSM genitourinary syndrome of menopause, $V M S$ vasomotor symptoms, $V V A$ vulvovaginal atrophy

${ }^{a}$ Adapted from Cancer Care Ontario recommendations. Available from: https://www.cancercareontario.ca/en/content/interventions-addresssexual-problems-people-cancer

${ }^{\mathrm{b}}$ Co-sponsored by The Australasian Menopause Society, British Menopause Society, European Menopause and Andropause Society, European Society of Endocrinology, and the International Menopause Society

${ }^{\mathrm{c}}$ Endorsed by the American Society for Reproductive Medicine, American Congress of Obstetricians and Gynecologists, European Society of Endocrinology, and the International Menopause Society

${ }^{\mathrm{d}}$ Endorsed by the Academy of Women's Health, American Association of Clinical Endocrinologists, American Association of Nurse Practitioners, American Medical Women's Association, American Society for Reproductive Medicine, Asociación Mexicana para el Estudio del Climaterio, Association of Reproductive Health Professionals, Australasian Menopause Society, Chinese Menopause Society, Colegio Mexicano de Especialistas en Ginecologia y Obstetricia, Czech Menopause and Andropause Society, Dominican Menopause Society, European Menopause and Andropause Society, German Menopause Society, Groupe d'études de la ménopause et du vieillissement Hormonal, HealthyWomen, Indian Menopause Society, International Menopause Society, International Osteoporosis Foundation, International Society for the Study of Women's Sexual Health, Israeli Menopause Society, Japan Society of Menopause and Women's Health, Korean Society of Menopause, Menopause Research Society of Singapore, National Association of Nurse Practitioners in Women's Health, SOBRAC and FEBRASGO, SIGMA Canadian Menopause Society, Società Italiana della Menopausa, Society of Obstetricians and Gynaecologists of Canada, South African Menopause Society, Taiwanese Menopause Society, and the Thai Menopause Society. The American College of Obstetricians and Gynecologists supports the value of this clinical document as an educational tool, June 2017. The British Menopause Society supports this Position Statement

\section{Available Treatments}

In 2003, the US Food and Drug Administration (FDA) issued a clinical guidance to the pharmaceutical industry concerning enrollment for studies of estrogen and estrogen/progestin drug products for the treatment of moderate-to-severe VMS and VVA associated with menopause. For approval and labeling of drugs intended to treat VMS or VVA, the FDA requires that study participants self-identify at least one moderate-to-severe symptom that is their most bothersome, have $\leq 5 \%$ superficial cells on a vaginal smear, and a vaginal $\mathrm{pH}>5.0$ [27]. The most bothersome symptom must be either vaginal dryness, vaginal and/or vulvar irritation/ itching, dysuria, vaginal pain associated with sexual activity, or vaginal bleeding associated with sexual activity. The result of this guidance is that products approved after 2003 are approved for a single symptom. The FDA also requires a boxed warning on the label of all products containing estrogen, indicating that they may slightly increase the risk of heart attack, stroke, breast cancer, and blood clots [28].

\subsection{Pharmacologic Treatments}

Several forms of ET are available. Systemic dosage forms include capsules/tablets and transdermal preparations and one vaginal ring; local administration is primarily accomplished via the vaginal route [29]. Vaginal therapy is the first-line pharmacologic treatment recommended by NAMS [30] and the International Menopause Society [21] for GSM. Most societies recommend that women be treated with the lowest dose and frequency that effectively manages their symptoms [31]. See Table 2 for additional information on the therapies discussed below. 


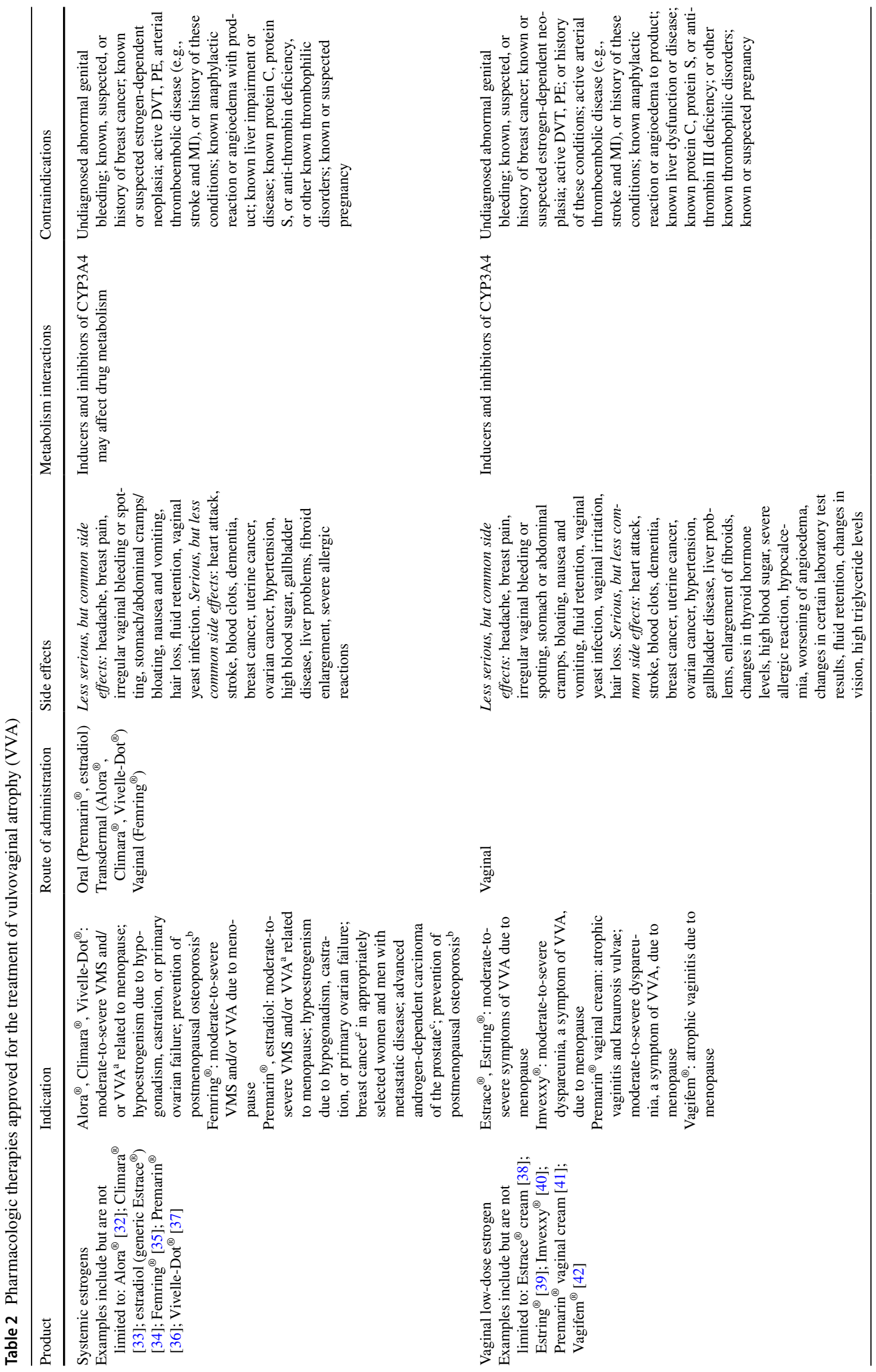




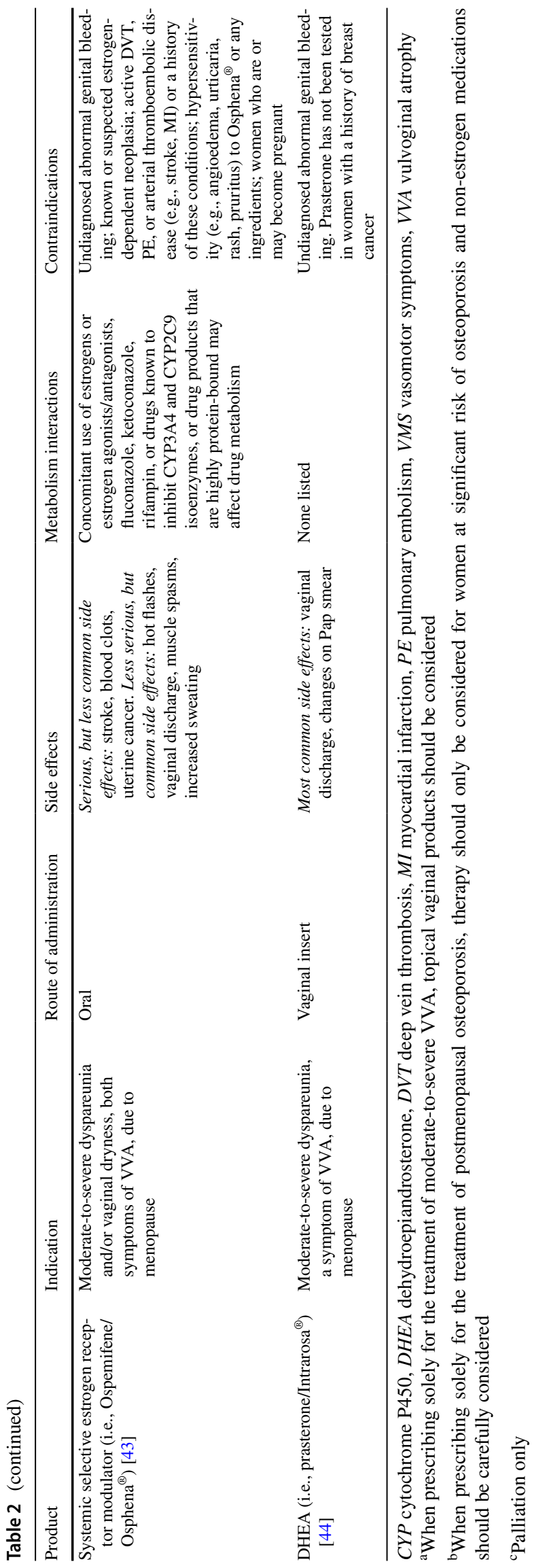

\subsection{Systemic Therapy}

Systemic ET is the mainstay treatment for VMS and may also alleviate concurrent GSM. When VMS and VVA symptoms occur concomitantly and require management, treatment is typically estrogen alone for hysterectomized women or estrogen with progestogen or conjugated equine estrogens/ bazedoxifene (Duavee ${ }^{\circledR}$ ) therapy for women with an intact uterus [45]. Conjugated equine estrogens/bazedoxifene is FDA-approved for VMS and the prevention of osteoporosis; although VVA is not an FDA-approved indication, clinical studies demonstrated that women also may experience some improvement in the signs and symptoms of GSM, particularly lubrication and sexual function [46, 47]. It is important to recognize that if VMS has subsided and symptoms are limited to GSM, vaginal treatment is recommended.

\subsection{Vaginal Therapy}

Vaginal ET is the recommendation for women with only vaginal symptoms as it allows for lower doses of estrogen than used in systemic therapy for VMS [48]. A progestogen is generally not indicated when ET is administered in low doses vaginally [15]. Endometrial surveillance is not required with vaginal ET unless there is postmenopausal bleeding, which would require diagnostic evaluation [16].

Low-dose vaginal ET is available in a variety of forms, including cream (Premarin ${ }^{\circledR}$, Estrace $^{\circledR}$, a sustained-release [90-day] ring (Estring $\left.{ }^{\circledR}\right)$, vaginal tablets $\left(\right.$ Vagifem $\left.^{\circledR}\right)$, and a soft-gel estradiol insert $\left(\operatorname{Imvexxy}{ }^{\circledR}\right)$. There are also FDAapproved generic forms of Vagifem ${ }^{\circledR}$ and Estrace ${ }^{\circledR}$. Of note, a different vaginal ring, Femring ${ }^{\circledR}$, is FDA-approved for both VMS and VVA and provides systemic ET, thus requiring a concomitant progestogen. Vaginal therapy can restore estrogen to the tissues and help reverse atrophic changes while minimizing systemic exposure [48]. Other changes include an increase in the vaginal rugae, an increase in the number of lactobacilli, and improvements in the vaginal and urethral epithelium [30, 49]. Four systematic efficacy and safety reviews of vaginal estrogen products for treating moderateto-severe GSM reported them to be superior to placebo in achieving maturation of vaginal epithelium, a reduction in vaginal $\mathrm{pH}$, and improved dyspareunia, vaginal dryness, and urogenital symptoms with minimal safety concerns. Across all studies, $4 \mu \mathrm{g}$ was the lowest safe and effective dose [50-53]. It must be noted, however, that none of the studies were sufficiently powered or long enough to identify longterm side effects. A Cochrane Review showed no evidence of a difference in the proportion of women who reported improvement in symptoms of VVA between the following treatments: estrogen ring and estrogen cream, estrogen ring and estrogen tablets, estrogen tablets and estrogen cream, and estrogen cream and isoflavone gel. A higher proportion 
of women reported an improvement in symptoms with the estrogen ring, estrogen tablets, and estrogen cream compared with placebo [29]. Although vaginal ET reduces symptoms of VVA, the systemic exposure is low enough that it does not alleviate VMS or reduce the risk of osteoporosis [49]. Recent studies have not shown an elevated risk of cardiovascular disease [54, 55], cancer (endometrial [54-56], breast [54, 55], ovarian, or colorectal [54]) or hip fracture [54].

The MsFLASH GSM study was a 12-week trial comparing the efficacy of $10-\mu \mathrm{g}$ vaginal estradiol tablet plus placebo gel, placebo tablet plus vaginal moisturizer, or placebo tablet plus placebo moisturizer in 302 postmenopausal women with moderate-to-severe vulvovaginal symptoms. The investigators found no difference among the three treatments on the primary outcome of the severity of participants' most bothersome symptom. They concluded that postmenopausal women with vulvovaginal symptoms "should choose the least expensive over-the-counter (OTC) product" [57]. This short (3-month) study examined several different symptoms as a single entity instead of examining a single symptom such as dyspareunia. Its results should not override the results of many robust randomized controlled trials showing the benefit of vaginal estrogen for GSM [58]. Women with GSM who are considering OTC treatment should be informed that while introital pain and vaginal dryness may initially respond to such treatment, these products may not reverse or halt the underlying pathophysiological processes involved in GSM and will not provide long-term symptom management.

\subsection{Prasterone}

Androgens (i.e., dehydroepiandrosterone [DHEA], androstenedione, and testosterone) are a necessary precursor for the biosynthesis of estrogens. In healthy premenopausal women, androgen production is significantly greater than that of estrogens [22]. Androgen receptors are widespread throughout the genitourinary tract [22]. Androgen-dependent protein products exert trophic effects on various genitourinary tissues (vestibule, clitoris, urethra, vagina, bladder, muscles/ ligaments in pelvic floor) and are thought to independently regulate vaginal health such as vaginal and vestibular lubrication, smooth muscle activity, and blood flow. In addition to the cessation of estrogen production during menopause, decreasing androgens with advancing age can be a contributory factor in the development of the signs and symptoms of GSM $[22,59,60]$.

Prasterone (Intrarosa ${ }^{\circledR}$ ) is a synthetic equivalent to endogenous DHEA approved for the treatment of moderate-tosevere dyspareunia [22]. Pre-clinical studies of prasterone have found improvements on the collagen and muscularis layers of vaginal tissues, as well as increased nerve density in the vagina [61]. Prasterone is administered as a vaginal insert once daily at bedtime, does not carry a boxed warning, and has no restrictions on duration of use [44]. Use of prasterone is associated with significant improvements in vaginal epithelial cells, vaginal $\mathrm{pH}$, parabasal cells, and the severity of vaginal symptoms; serum levels of estradiol and testosterone remain within normal limits. Moderate-tosevere dyspareunia, vaginal dryness, and irritation/itching also improve. Visual examination shows improvement in vaginal secretions, color, epithelial surface thickness, and epithelial integrity. The endometrial safety of intravaginal prasterone has been shown in short- and long-term trials [62-65]. The most common adverse event $(\geq 2 \%)$ in four 12 -week randomized controlled trials was vaginal discharge. In the 52-week open-label trial, the most common adverse events $(\geq 2 \%)$ were vaginal discharge and abnormal Pap smear [44]. Prasterone has not been tested in women with breast cancer or with a history of breast cancer.

\subsection{Ospemifene}

Ospemifene (Osphena $\left.{ }^{\circledR}\right)$ is an orally administered selective estrogen receptor modulator approved for the treatment of moderate-to-severe dyspareunia and moderate-to-severe vaginal dryness, both symptoms of VVA due to menopause [43]. Preclinical data have demonstrated that ospemifene may have a beneficial estrogenic effect on bone and an antiestrogenic effect on breast tissue; however, ospemifene is not approved for osteoporosis prevention or use in breast cancer [66]. Ospemifene has a boxed warning that is a modification of the class labeling mandated by the FDA for estrogenbased products [43, 66]. Ospemifene (60-mg dose) reduces the severity of dyspareunia and has beneficial effects for vaginal dryness and bone as well as anti-estrogenic effects on breast tissue. The most common side effect is hot flashes. Other adverse events include: vaginal discharge, muscle spasm, genital discharge, and hyperhidrosis [43]. Compared with placebo, ospemifene decreases vaginal $\mathrm{pH}$, reduces parabasal cells, and increases superficial cells [67]. A metaanalysis of the ospemifene randomized trials suggested that it is well tolerated with a good safety profile [68].

\subsection{Other Products}

\subsubsection{Compounded Preparations}

The FDA-required boxed warning for all ETs has led to an upsurge in interest in compounded hormones owing to their perceived lack of risk [14]. Compounded bioidentical hormone therapy products do not undergo the rigorous testing required of FDA-approved therapies and do not have a boxed warning [27, 69]. The Endocrine Society, NAMS, the American College of Obstetricians and Gynecologists, the American Society for Reproductive Medicine, and the 
International Menopause Society all recommend against the use of compounded bioidentical hormone therapy by anyone without a medical condition preventing them from using FDA-approved products $[15,16]$. The FDA has also issued caution against their use, citing concerns surrounding purity, potency and quality, the lack of efficacy and safety studies, and inadequate labeling [69].

\subsubsection{Estriol}

Estriol is a relatively weak natural estrogen that is used outside the US to treat GSM. Brand names include Ovestin ${ }^{\circledR}$ and Gynest ${ }^{\circledR}$. A low-dose estriol vaginal gel formulation $(0.005 \%$ estriol vaginal gel) has been shown to significantly increase vaginal maturation index and improve vaginal $\mathrm{pH}$ compared with a baseline evaluation in postmenopausal women [70]. A combination of low-dose estriol and lyophilized viable Lactobacillus acidophilus tablet appears effective for relieving GSM symptoms, reducing urogenital atrophy, and restoring vaginal flora [71]. Estriol is not approved by the FDA for any indication.

\subsection{Treating Genitourinary Syndrome of Menopause in Women with a History of, Active, or High Risk for Breast Cancer}

Breast cancer is the most common cancer in US women with an estimated 250,000 women, mostly postmenopausal, diagnosed in 2017. The median age at diagnosis is 62 years and most tumors are hormone-receptor positive. More than $60 \%$ of postmenopausal patients with breast cancer report symptoms of VVA, notably vaginal dryness and dyspareunia [72]. According to the consensus guidelines approved by NAMS and the International Society for the Study of Women's Sexual Health, women with or at high risk for breast cancer should be offered non-hormonal therapies (e.g., moisturizers, lubricants, pelvic floor physical therapy, dilator therapy) as first-line treatments for symptom management. Women at high risk for breast cancer whose symptoms have not responded to non-hormone therapies may be offered low-dose vaginal hormone therapies, as may women with ER-positive breast cancers who are taking tamoxifen with persistent and severe symptoms, provided they have factors indicating a low risk of recurrence [26]. Women with ER-positive breast cancers who are taking aromatase inhibitors may be candidates for low-dose vaginal hormone therapies after consultation with their oncologist and a thorough discussion of risks and benefits, recognizing that even small amounts of estrogen absorbed might impact the effectiveness of the aromatase inhibitor. The use of vaginal hormone therapy in women with a history of triple-negative disease is theoretically reasonable, but data are lacking. Among women with metastatic disease, the decision to use low-dose vaginal hormone therapy should consider quality of life and potential length of survival [26].

The American College of Obstetricians and Gynecologists recommends the use of non-hormonal options as the first choice for treatment of vaginal atrophy in women with current or a history of estrogen-dependent breast cancer; however, they also consider vaginal ET appropriate for patients with a history of estrogen-dependent breast cancer who are unresponsive to non-hormonal remedies, but only after a thorough discussion of risks and benefits [73]. In their 2018 Practice Guideline titled "Interventions to Address Sexual Problems in People with Cancer," the American Society of Clinical Oncology recommends non-hormonal therapies as the initial treatment for all women with cancer and cancer survivors. For those who do not respond or whose symptoms are more severe at presentation, low-dose vaginal estrogen can be used. For women with hormone-positive breast cancer who are symptomatic and not responding to conservative measures, low-dose vaginal estrogen can be considered after a thorough discussion of risks and benefits. For women with current or a history of breast cancer who are taking aromatase inhibitors and have not responded to previous treatment, clinicians may offer vaginal DHEA [18].

Ospemifene has not been adequately studied in women with or with a history of breast cancer; therefore, it should not be used in women with known or suspected breast cancer [43]. Prasterone has not been studied in women with a history of breast cancer [44]; however, in one recent study using compounded DHEA, women reported improved sexual function as well as mean post-treatment pain scores in the normal range [74].

\section{Adjunctive Treatments}

\subsection{Lubricants/Moisturizers}

For women reluctant to use vaginal estrogen, non-hormonal lubricants and moisturizers are often recommended to provide short-term relief from mild-to-moderate vaginal dryness and dyspareunia. Lubricants, which are available in water-, silicone-, mineral-, or plant oil-based forms, are applied to the vagina and vulva prior to sex [75]. Waterbased lubricants are often preferred over oil-based lubricants as they are non-staining and associated with fewer genital symptoms [76]. Women should choose a product that is optimally balanced in terms of both osmolality and $\mathrm{pH}$ and physiologically most similar to natural vaginal secretions [75]. The World Health Organization recommends that the osmolality of a personal lubricant not exceed $380 \mathrm{mOsm} / \mathrm{kg}$ to minimize any risk of epithelial damage (mucosal irritation and tissue damage) or cytotoxicity. However, an upper limit of $1200 \mathrm{mOsm} / \mathrm{kg}$ is generally deemed acceptable. Vaginal 
lubricants should have a pH of about 4.5 [77]. Vaginal moisturizers rehydrate dry mucosal tissue, are absorbed into the skin, and adhere to the vaginal lining, thereby mimicking natural vaginal secretions. They can be used several times per week independent of sexual activity. Their effects are more long-term than lubricants and are intended for the alleviation of vaginal dryness/atrophic vaginitis/VVA. Both types of product can be used in combination with other GSM treatments [75]. However, patients should be informed that OTC products do not treat the underlying cause of VVA and thus cannot halt or reverse the progression of GSM. Women should be given information concerning all options. It has been suggested that a prescription be provided so that treatment is not delayed should OTC products fail to provide sufficient relief [78].

\subsection{Hyaluronic Acid}

Vaginal hyaluronic acid is a colorless gel that contains a derivative of hyaluronic acid that releases water molecules to the tissue, thus alleviating vaginal dryness without irritating the vaginal mucosa. The FDA currently regulates hyaluronic acid products as medical devices. Although several studies have suggested that hyaluronic acid may be useful in the treatment of GSM, the studies are small and lack rigor [79-81].

\subsection{Physical Therapy/Dilators}

Women with VVA and vaginal constriction may benefit from gentle stretching of the vagina with the use of lubricated dilators of graduated sizes. They may also benefit from pelvic floor physical therapy [24]. Pelvic floor muscle therapy may be useful for the treatment of non-relaxing or high-tone pelvic floor muscle dysfunction triggered by painful sexual activity related to GSM [31], or as a complementary treatment in women with persistent dyspareunia. It has been shown to be an effective treatment for urinary incontinence, genital prolapse, dyspareunia, and relief of VVA symptoms [82].

\subsection{Laser Therapy}

Laser therapy, with either a fractional $\mathrm{CO}_{2}$ laser or erbium:YAG laser, has been proposed as a non-hormonal therapy for GSM [83]. Several small studies have shown that fractional $\mathrm{CO}_{2}$ laser therapy can restore the vaginal epithelium to a state similar to the premenopausal state, increase the amounts of Lactobacillus and other premenopausal flora, as well as improve the Vaginal Health Index score and subjective symptoms of GSM, including lower urinary tract symptoms $[49,84]$. The use of the erbium:YAG laser has been shown to improve symptoms of GSM and stress urinary incontinence [84]. These studies lack randomization, were not blinded, and did not include a control group. Although limited data with laser therapy in postmenopausal women with GSM who are survivors of breast cancer suggest it has the potential to be helpful without increasing the risk of cancer recurrence [26], the FDA has not approved fractional $\mathrm{CO}_{2}$ laser therapy and warns against use for the treatment of VVA without long-term well-controlled studies [85]. There remain many unanswered issues with laser therapy including high cost and affordability, long-term efficacy and safety, and patient access to treatment $[85,86]$.

\section{Patient Perspectives}

Appropriate treatment of GSM is dependent on open and effective communication between women and their HCPs, yet surveys show that many women are reluctant to initiate discussion of their symptoms $[1,87,88]$ and HCPs are hesitant to inquire about symptoms [89]. Women give many reasons for their reluctance, including embarrassment, belief that nothing can be done medically, feeling that discussion might be inappropriate to have with the HCP, belief that the HCP is too busy, and fear that their HCP would be embarrassed [1]. Adherence and satisfaction are improved when women are involved in the decision-making process and there is a good rapport between patient and HCP. Women should be informed about the many treatment options available for VVA-related symptoms and encouraged to make choices based on their personal preferences and needs [78]. Clinicians can provide valuable education with a brief but detailed discussion of anatomy and a demonstration of atrophic changes, perhaps using a gynecologic examination as a prompt [48]. In the EMPOWER survey, women indicated a preference for a VVA symptoms questionnaire that could be completed before talking with their HCP [90].

More than half of the participants in the EMPOWER study chose their VVA treatment based on the recommendation of their HCP [90]. Surveys have shown that when women chose to treat their VVA symptoms, they opted for vaginal lubricants or moisturizers, although satisfaction with these products remains low [91]. Treatment choice hinged on a perceived risk of systemic absorption, messiness of application, and the need to reuse an applicator [90]. The main barriers to the use of vaginal ET for GSM are patient perceptions of safety and the communication barriers between HCPs and their patients [48]. Much of the concern with safety appears to stem from the presence of the boxed warning; NAMS and other organizations and experts have advocated for modification of this labeling for vaginal estrogen [92]. However, the FDA has stated that there is no defined threshold of systemic exposure at which exogenous estrogen is known to be associated with fewer or no adverse events. When participants in the REVIVE study were asked about 
preferences regarding the method of treatment for their VVA symptoms, they indicated a preference for oral or vaginal treatment. An oral treatment was highly preferred among younger patients as well as those patients who had never used any VVA treatment, while there was no difference in these treatment choices among women currently using a treatment for VVA symptoms [78]. Women in the REVIVE study who discontinued VVA treatment frequently noted insufficient symptom relief. Inadequate instructions on how to administer products and inconsistent use may also contribute to unsatisfactory results [9]. In the REVIVE study, of the $39.2 \%$ of participants who discontinued therapy, about $10.4 \%$ did so because of the expense of treatment [93].

\section{Healthcare Provider Perspective}

In the WISDOM survey, the most common VVA treatment recommended by physicians was prescription therapy (alone or with other therapies), followed by OTC products alone, no treatment, behavioral/lifestyle management alone, and vaginal laser therapy alone [72]. Reasons given for these choices were efficacy, patient out-of-pocket cost, patient preference, and ease of use. Physicians in this study believed that women discontinue treatment because of cost, lack of symptom improvement, and concerns about long-term estrogen exposure. Approximately $40 \%$ of HCPs stated that their ability to treat VVA was limited by the currently available choices and that VVA therapy was only required if the symptoms negatively impacted the patient's quality of life. Most were comfortable prescribing vaginal ET for menopausal women, believed that it is preferable over other types of therapies for VVA, and that it is important to use the lowest effective dose of hormone therapy. Most were comfortable prescribing existing VVA therapies to women with no personal history or predisposition of breast cancer but were less comfortable doing so for women with a personal history of breast cancer [72].

\section{Cost}

In May 2018, the Centers for Medicare and Medicaid Services announced that drugs for the treatment of moderate-tosevere dyspareunia due to menopause are no longer excluded from Medicare Part D coverage, when used consistent with this labeling. While this eventually may reduce the out-ofpocket costs for many women covered under Medicare, other plans are not compelled to provide coverage. Thus, drug choice may be limited. Over-the-counter products and alternative therapies are generally not covered by any plan. Laser therapy and HA are not covered for the treatment of GSM as they are not approved for that indication.

\section{Summary and Conclusions}

Genitourinary syndrome of menopause is a unique set of symptoms and signs experienced by $>50 \%$ of women as they enter their postmenopausal years. The signs and symptoms of GSM are well established as is their impact on quality of life; unfortunately, many women remain unaware that it is a defined medical condition that can be treated. In 2014, NAMS and the International Society for the Study of Women's Sexual Health formally endorsed the term GSM, a more accurate and acceptable concept that included the genitourinary tract symptoms and signs related to menopause. There are numerous available treatments, each with benefits and limitations. However, many women remain unsatisfied with their choices and look forward to a simple treatment that is safe and effective. Women need to be vocal about their concerns and needs, and clinicians need to be open and available concerning postmenopausal issues.

\section{Compliance with Ethical Standards}

Funding Writing and editorial assistance was provided by Maria B. Vinall of The Curry Rockefeller Group, LLC, Tarrytown, NY, USA and paid for by AMAG Pharmaceuticals.

Conflict of interest Risa Kagan reports grants from Therapeutics MD and Endoceutics, paid to Sutter Research Institute, and was a principal investigator on clinical trials, has received consulting fees from AMAG, Therapeutics MD, Duschesnay, P\&G, and Allergan and payment for lectures from AMAG and Therapeutics MD. Susan KelloggSpadt reports consulting and speakers bureau fees from AMAG, Lupin, Therapeutics MD, and JDS Therapeutics. Sharon J. Parish reports consultation fees from AMAG, Allergen, Duchesnay Pharmaceuticals, JDS Therapeutics, Strategic Science Technologies, and Therapeutics $\mathrm{MD}$ and an honorarium for the Scientific Advisory Board from Sprout Pharmaceuticals, has served on the speakers bureau of AMAG Pharmaceuticals, and as a legal consultant for O'Brien and Ryan.

Open Access This article is distributed under the terms of the Creative Commons Attribution-NonCommercial 4.0 International License (http://creativecommons.org/licenses/by-nc/4.0/), which permits any noncommercial use, distribution, and reproduction in any medium, provided you give appropriate credit to the original author(s) and the source, provide a link to the Creative Commons license, and indicate if changes were made.

\section{References}

1. Parish SJ, Nappi RE, Krychman ML, Kellogg-Spadt S, Simon JA, Goldstein JA, et al. Impact of vulvovaginal health on postmenopausal women: a review of surveys on symptoms of vulvovaginal atrophy. Int J Womens Health. 2013;5:437-47. https://doi. org/10.2147/ijwh.s44579.

2. Portman DJ, Gass ML. Genitourinary syndrome of menopause: new terminology for vulvovaginal atrophy from the International Society for the Study of Women's Sexual Health and The North American Menopause Society. Menopause. 2014;21(10):1063-8. https://doi.org/10.1097/gme.0000000000000329. 
3. Palacios S, Nappi RE, Bruyniks N, Particco M, Panay N. The European Vulvovaginal Epidemiological Survey (EVES): prevalence, symptoms and impact of vulvovaginal atrophy of menopause. Climacteric. 2018;21(3):286-91. https://doi. org/10.1080/13697137.2018.1446930.

4. Nappi RE, Kokot-Kierepa M. Vaginal Health: Insights, Views \& Attitudes (VIVA): results from an international survey. Climacteric. 2012;15(1):36-44. https://doi.org/10.3109/13697 137.2011.647840.

5. Gandhi J, Chen A, Dagur G, Suh Y, Smith N, Cali B, et al. Genitourinary syndrome of menopause: an overview of clinical manifestations, pathophysiology, etiology, evaluation, and management. Am J Obstet Gynecol. 2016;215(6):704-11. https://doi. org/10.1016/j.ajog.2016.07.045.

6. Moral E, Delgado JL, Carmona F, Caballero B, Guillan C, Gonzalez PM, et al. The impact of genitourinary syndrome of menopause on well-being, functioning, and quality of life in postmenopausal women. Menopause. 2018;25(12):1418-23. https://doi. org/10.1097/gme.0000000000001148.

7. Simon JA, Kokot-Kierepa M, Goldstein J, Nappi RE. Vaginal Health in the United States: results from the Vaginal Health: Insights Views \& Attitudes survey. Menopause. 2013;20(10):10438. https://doi.org/10.1097/GME.0b013e318287342d.

8. Simon JA, Nappi RE, Kingsberg SA, Maamari R, Brown V. Clarifying vaginal atrophy's impact on sex and relationships (CLOSER) survey: emotional and physical impact of vaginal discomfort on North American postmenopausal women and their partners. Menopause. 2014;21(2):137-42. https://doi.org/10.1097/ GME.0b013e318295236f.

9. Kingsberg SA, Wysocki S, Magnus L, Krychman ML. Vulvar and vaginal atrophy in postmenopausal women: findings from the REVIVE (REal Women's VIews of Treatment Options for Menopausal Vaginal ChangEs) survey. J Sex Med. 2013;10(7):1790-9. https://doi.org/10.1111/jsm.12190.

10. Cumming GP, Herald J, Moncur R, Currie H, Lee AJ. Women's attitudes to hormone replacement therapy, alternative therapy and sexual health: a web-based survey. Menopause Int. 2007;13(2):79-83. https://doi.org/10.1258/175404507780796424.

11. Brotman RM, Shardell MD, Gajer P, Fadrosh D, Chang K, Silver MI, et al. Association between the vaginal microbiota, menopause status, and signs of vulvovaginal atrophy. Menopause. 2018;25(11):1321-30. https://doi.org/10.1097/gme.0000000000 001236.

12. Muhleisen AL, Herbst-Kralovetz MM. Menopause and the vaginal microbiome. Maturitas. 2016;91:42-50. https://doi.org/10.1016/j. maturitas.2016.05.015.

13. Rossouw JE, Anderson GL, Prentice RL, LaCroix AZ, Kooperberg C, Stefanick ML, et al. Risks and benefits of estrogen plus progestin in healthy postmenopausal women: principal results from the Women's Health Initiative randomized controlled trial. JAMA. 2002;288(3):321-33.

14. Simon JA. The Woman's Health Initiative and one of many unintended consequences. Menopause. 2016;23(10):1057-9. https:// doi.org/10.1097/gme.0000000000000749.

15. North American Menopause Society. The 2017 hormone therapy position statement of The North American Menopause Society. Menopause. 2017;24(7):728-53. https://doi.org/10.1097/ gme.0000000000000921.

16. American College of Obstetrics and Gynecology. ACOG Practice Bulletin No. 141: management of menopausal symptoms. Obstet Gynecol. 2014;123(1):202-16. https://doi.org/10.1097/01. aog.0000441353.20693.78.

17. American College of Obstetrics and Gynecology. ACOG Practice Bulletin No. 126: management of gynecologic issues in women with breast cancer. Obstet Gynecol. 2012;119(3):666-82. https:// doi.org/10.1097/aog.0b013e31824e12ce.
18. Carter J, Lacchetti C, Andersen BL, Barton DL, Bolte S, Damast $\mathrm{S}$, et al. Interventions to address sexual problems in people with cancer: American Society of Clinical Oncology Clinical Practice Guideline Adaptation of Cancer Care Ontario Guideline. J Clin Oncol. 2018;36(5):492-511. https://doi.org/10.1200/ jco.2017.75.8995.

19. Stuenkel CA, Davis SR, Gompel A, Lumsden MA, Murad MH, Pinkerton JV, et al. Treatment of symptoms of the menopause: an Endocrine Society clinical practice guideline. J Clin Endocrinol Metab. 2015;100(11):3975-4011. https://doi.org/10.1210/ jc.2015-2236.

20. Wierman ME, Arlt W, Basson R, Davis SR, Miller KK, Murad $\mathrm{MH}$, et al. Androgen therapy in women: a reappraisal: an Endocrine Society clinical practice guideline. J Clin Endocrinol Metab. 2014;99(10):3489-510. https://doi.org/10.1210/jc.2014-2260.

21. Baber RJ, Panay N, Fenton A. 2016 IMS recommendations on women's midlife health and menopause hormone therapy. Climacteric. 2016;19(2):109-50. https://doi.org/10.3109/13697 137.2015.1129166.

22. Simon JA, Goldstein I, Kim NN, Davis SR, Kellogg-Spadt S, Lowenstein $\mathrm{L}$, et al. The role of androgens in the treatment of genitourinary syndrome of menopause (GSM): International Society for the Study of Women's Sexual Health (ISSWSH) expert consensus panel review. Menopause. 2018;25(7):837-47. https:// doi.org/10.1097/gme.0000000000001138.

23. National Comprehensive Cancer Network. NCCN Clinical Practice Guidelines in Oncology (NCCN Guidelines ${ }^{\circledR}$ ) Survivorship, Version 2.2019. https://www.nccn.org/professionals/physician_ gls/pdf/survivorship.pdf. Accessed 31 July 2019.

24. North American Menopause Society. Management of symptomatic vulvovaginal atrophy: 2013 position statement of The North American Menopause Society. Menopause. 2013;20(9):888-902. https://doi.org/10.1097/gme.0b013e3182a122c2 (quiz 3-4).

25. North American Menopause Society. Nonhormonal management of menopause-associated vasomotor symptoms: 2015 position statement of The North American Menopause Society. Menopause. 2015;22(11):1155-72. https://doi.org/10.1097/gme.00000 00000000546 (quiz 73-4).

26. Faubion SS, Larkin LC, Stuenkel CA, Bachmann GA, Chism LA, Kagan R, et al. Management of genitourinary syndrome of menopause in women with or at high risk for breast cancer: consensus recommendations from The North American Menopause Society and The International Society for the Study of Women's Sexual Health. Menopause. 2018;25(6):596-608. https://doi.org/10.1097/ gme.0000000000001121.

27. US Food and Drug Administration. Guidance for industry: estrogen and estrogen/progestin drug products to treat vasomotor symptoms and vulvar and vaginal atrophy symptoms: recommendations for clinical evaluation. 2003. http://www.fda.gov/downl oads/drugs/guidancecomplianceregulatoryinformation/guidances/ ucm071643.pdf). Accessed 6 Dec 2017.

28. Jeffrey S. Estrogen formulations get FDA "black-box" warning. Medscape. 2003. https://www.medscape.com/viewarticle/78584 0 . Accessed 25 June 2019.

29. Lethaby A, Ayeleke RO, Roberts H. Local oestrogen for vaginal atrophy in postmenopausal women. Cochrane Database Syst Rev. 2016;8:CD001500. https://doi.org/10.1002/14651858.cd001500. pub3.

30. North American Menopause Society. The role of local vaginal estrogen for treatment of vaginal atrophy in postmenopausal women: 2007 position statement of The North American Menopause Society. Menopause. 2007;14(3 Pt 1):355-69. https://doi. org/10.1097/gme.0b013e31805170eb (quiz 70-1).

31. Faubion SS, Sood R, Kapoor E. Genitourinary syndrome of menopause: management strategies for the clinician. Mayo Clin 
Proc. 2017;92(12):1842-9. https://doi.org/10.1016/j.mayoc p.2017.08.019.

32. Allergan USA. ALORA ${ }^{\circledR}$ (Estradiol Transdermal System, USP). Prescribing Information. 2018. https://www.allergan.com/assets/ pdf/alora_pi.

33. Bayer HealthCare Pharmaceuticals Inc. Climara ${ }^{\circledR}$ (estradiol transdermal system). Prescribing Information. 2013. http://labeling. bayerhealthcare.com/html/products/pi/Climara_PI.pdf.

34. Teva Pharmaceuticals USA Inc. ESTRADIOL- estradiol tablet. 2018. https://dailymed.nlm.nih.gov/dailymed/drugInfo.cfm?setid $=c 4936878-1643-4 e 7 f-9 b 0 d-e 4957935 a e f 2$.

35. Allergan USA I. Femring ${ }^{\circledR}$ (estradiol acetate vaginal ring): prescribing information. 2017. https://www.allergan.com/assets/pdf/ femring_pi. Accessed 12 Mar 2019.

36. Pfizer. Premarin (conjugated estrogens) tablets: prescribing information. 2018. http://labeling.pfizer.com/showlabeli ng.aspx?id=131. Accessed 12 Mar 2019.

37. Novartis Pharmaceuticals Corp. VIVELLE-DOT ${ }^{\circledR}$ (estradiol transdermal system). Prescribing Information. 2017. https://www. pharma.us.novartis.com/sites/www.pharma.us.novartis.com/files /Vivelle_DOT.pdf.

38. Allergan USA I. Estrace ${ }^{\circledR}$ cream (estradiol vaginal cream, USP, $0.01 \%$ ): prescribing information. 2018. https://www.allergan.com/ assets/pdf/estrace_pi. Accessed 12 Mar 2019.

39. Pfizer. ESTRING ${ }^{\circledR}$ (estradiol vaginal ring). Prescribing Information. 2017. http://labeling.pfizer.com/ShowLabeling.aspx?id=567.

40. TherapeuticsMD Inc. Imvexxy (estradiol vaginal inserts) Prescribing Information (May). 2018. https://imvexxy.com/pi.pdf?utm medium $=$ dir_org\&utm_source $=$ dir_org\&utm_campaign $=$ undef ined\&utm_content=undefined\&utm_term $=$ dir_org.

41. Pfizer. Premarin (conjugated estrogens) vaginal cream: prescribing information. 2018. http://labeling.pfizer.com/showlabeli ng.aspx?id=132. Accessed 12 Mar 2019.

42. Novo Nordisk Health Care AG. VAGIFEM ${ }^{\circledR}$ (estradiol vaginal inserts) Prescribing Information (August). 2016. https://www. novo-pi.com/vagifem.pdf.

43. Duchesnay Inc. Osphena (ospemifene) tablets: prescribing information. 2019.

44. AMAG Pharmaceuticals. Intrarosa (prasterone) vaginal insert. Prescribing Information. 2018. https://dailymed.nlm.nih.gov/dailymed/ drugInfo.cfm?setid=df731acd-7276-4fef-b037-bc7f30c112cb.

45. Parish SJ, Gillespie JA. The evolving role of oral hormonal therapies and review of conjugated estrogens/bazedoxifene for the management of menopausal symptoms. Postgrad Med. 2017;129(3):340-51. https://doi.org/10.1080/00325 481.2017.1281083.

46. Bachmann G, Bobula J, Mirkin S. Effects of bazedoxifene/ conjugated estrogens on quality of life in postmenopausal women with symptoms of vulvar/vaginal atrophy. Climacteric. 2010;13(2):132-40. https://doi.org/10.3109/13697130903305627.

47. Kagan R, Williams RS, Pan K, Mirkin S, Pickar JH. A randomized, placebo- and active-controlled trial of bazedoxifene/ conjugated estrogens for treatment of moderate to severe vulvar/vaginal atrophy in postmenopausal women. Menopause. 2010;17(2):281-9. https://doi.org/10.1097/GME.0b013e3181 b7c65f.

48. Kingsberg SA, Krychman ML. Resistance and barriers to local estrogen therapy in women with atrophic vaginitis. J Sex Med. 2013;10(6):1567-74. https://doi.org/10.1111/jsm.12120.

49. Naumova I, Castelo-Branco C. Current treatment options for postmenopausal vaginal atrophy. Int J Womens Health. 2018;10:38795. https://doi.org/10.2147/ijwh.s158913.

50. Biehl C, Plotsker O, Mirkin S. A systematic review of the efficacy and safety of vaginal estrogen products for the treatment of genitourinary syndrome of menopause. Menopause. 2019;26(4):431-53. https://doi.org/10.1097/GME.0000000000001221.
51. Rahn DD, Carberry C, Sanses TV, Mamik MM, Ward RM, Meriwether KV, et al. Vaginal estrogen for genitourinary syndrome of menopause: a systematic review. Obstet Gynecol. 2014;124(6):1147-56. https://doi.org/10.1097/aog.0000000000 000526.

52. Suckling J, Lethaby A, Kennedy R. Local oestrogen for vaginal atrophy in postmenopausal women. Cochrane Database Syst Rev. 2006;4:CD001500. https://doi.org/10.1002/14651858.cd001500. pub2.

53. Weber MA, Kleijn MH, Langendam M, Limpens J, Heineman MJ, Roovers JP. Local oestrogen for pelvic floor disorders: a systematic review. PLoS One. 2015;10(9):e0136265. https://doi. org/10.1371/journal.pone.0136265.

54. Bhupathiraju SN, Grodstein F, Stampfer MJ, Willett WC, Crandall CJ, Shifren JL, et al. Vaginal estrogen use and chronic disease risk in the Nurses' Health Study. Menopause. 2018;26(6):603-10. https://doi.org/10.1097/gme.0000000000001284.

55. Crandall CJ, Hovey KM, Andrews CA, Chlebowski RT, Stefanick ML, Lane DS, et al. Breast cancer, endometrial cancer, and cardiovascular events in participants who used vaginal estrogen in the Women's Health Initiative Observational Study. Menopause. 2018;25(1):11-20. https://doi.org/10.1097/gme.0000000000 000956.

56. Constantine GD, Graham S, Lapane K, Ohleth K, Bernick B, Liu J, et al. Endometrial safety of low-dose vaginal estrogens in menopausal women: a systematic evidence review. Menopause. 2019;26(7):800-7. https://doi.org/10.1097/gme.0000000000 001315.

57. Mitchell CM, Reed SD, Diem S, Larson JC, Newton KM, Ensrud $\mathrm{KE}$, et al. Efficacy of vaginal estradiol or vaginal moisturizer vs placebo for treating postmenopausal vulvovaginal symptoms: a randomized clinical trial. JAMA Intern Med. 2018;178(5):68190. https://doi.org/10.1001/jamainternmed.2018.0116.

58. Pinkerton JV, Kaunitz AM, Manson JE. Not time to abandon use of local vaginal hormone therapies. Menopause. 2018;25(8):8558. https://doi.org/10.1097/gme.0000000000001142.

59. Traish AM, Vignozzi L, Simon JA, Goldstein I, Kim NN. Role of androgens in female genitourinary tissue structure and function: implications in the genitourinary syndrome of menopause. Sex Med Rev. 2018;6(4):558-71. https://doi.org/10.1016/j. sxmr.2018.03.005.

60. Bell RJ, Rizvi F, Islam RM, Davis SR. A systematic review of intravaginal testosterone for the treatment of vulvovaginal atrophy. Menopause. 2018;25(6):704-9. https://doi.org/10.1097/ gme.0000000000001052.

61. Labrie F, Belanger A, Pelletier G, Martel C, Archer DF, Utian WH. Science of intracrinology in postmenopausal women. Menopause. 2017;24(6):702-12. https://doi.org/10.1097/gme.00000 00000000808

62. Archer DF, Labrie F, Bouchard C, Portman DJ, Koltun W, Cusan $\mathrm{L}$, et al. Treatment of pain at sexual activity (dyspareunia) with intravaginal dehydroepiandrosterone (prasterone). Menopause. 2015;22(9):950-63. https://doi.org/10.1097/gme.0000000000 000428 .

63. Archer DF, Labrie F, Montesino M, Martel C. Comparison of intravaginal $6.5 \mathrm{mg}(0.50 \%)$ prasterone, $0.3 \mathrm{mg}$ conjugated estrogens and $10 \mu \mathrm{g}$ estradiol on symptoms of vulvovaginal atrophy. J Steroid Biochem Mol Biol. 2017;174:1-8. https://doi. org/10.1016/j.jsbmb.2017.03.014.

64. Labrie F, Archer DF, Koltun W, Vachon A, Young D, Frenette L, et al. Efficacy of intravaginal dehydroepiandrosterone (DHEA) on moderate to severe dyspareunia and vaginal dryness, symptoms of vulvovaginal atrophy, and of the genitourinary syndrome of menopause. Menopause. 2016;23(3):243-56. https://doi.org/10.1097/ gme.0000000000000571. 
65. Portman DJ, Goldstein SR, Kagan R. Treatment of moderate to severe dyspareunia with intravaginal prasterone therapy: a review. Climacteric. 2019;22(1):65-72. https://doi.org/10.1080/13697 137.2018.1535583.

66. Simon JA, Altomare C, Cort S, Jiang W, Pinkerton JV. Overall safety of ospemifene in postmenopausal women from placebocontrolled phase 2 and 3 trials. J Womens Health (Larchmt). 2018;27(1):14-23. https://doi.org/10.1089/jwh.2017.6385.

67. Di Donato V, Schiavi MC, Iacobelli V, D’Oria O, Kontopantelis E, Simoncini T, et al. Ospemifene for the treatment of vulvar and vaginal atrophy: a meta-analysis of randomized trials. Part I: evaluation of efficacy. Maturitas. 2019;121:86-92. https://doi. org/10.1016/j.maturitas.2018.11.016.

68. Di Donato V, Schiavi MC, Iacobelli V, D'Oria O, Kontopantelis E, Simoncini T, et al. Ospemifene for the treatment of vulvar and vaginal atrophy: a meta-analysis of randomized trials. Part II: evaluation of tolerability and safety. Maturitas. 2019;121:93-100. https://doi.org/10.1016/j.maturitas.2018.11.017.

69. Pinkerton JV, Pickar JH. Update on medical and regulatory issues pertaining to compounded and FDA-approved drugs, including hormone therapy. Menopause. 2016;23(2):215-23. https://doi. org/10.1097/gme.0000000000000523.

70. Caruso S, Cianci S, Amore FF, Ventura B, Bambili E, Spadola S, et al. Quality of life and sexual function of naturally postmenopausal women on an ultralow-concentration estriol vaginal gel. Menopause. 2016;23(1):47-54. https://doi.org/10.1097/gme.00000 00000000485 .

71. Mueck AO, Ruan X, Prasauskas V, Grob P, Ortmann O. Treatment of vaginal atrophy with estriol and lactobacilli combination: a clinical review. Climacteric. 2018;21(2):140-7. https://doi. org/10.1080/13697137.2017.1421923.

72. Kingsberg SA, Larkin L, Krychman M, Parish SJ, Bernick B, Mirkin S. WISDOM survey: attitudes and behaviors of physicians toward vulvar and vaginal atrophy (VVA) treatment in women including those with breast cancer history. Menopause. 2019;26(2):124-31. https://doi.org/10.1097/GME.0000000000001194.

73. American College of Obstetrics and Gynecology. ACOG Committee Opinion No. 659: the use of vaginal estrogen in women with a history of estrogen-dependent breast cancer. Obstet Gynecol. 2016;127(3):e93-6. https://doi.org/10.1097/aog.0000000000 001351.

74. Barton DL, Sloan JA, Shuster LT, Gill P, Griffin P, Flynn K, et al. Evaluating the efficacy of vaginal dehydroepiandosterone for vaginal symptoms in postmenopausal cancer survivors: NCCTG N10C1 (Alliance). Support Care Cancer. 2018;26(2):643-50. https://doi.org/10.1007/s00520-017-3878-2.

75. Edwards D, Panay N. Treating vulvovaginal atrophy/genitourinary syndrome of menopause: how important is vaginal lubricant and moisturizer composition? Climacteric. 2016;19(2):151-61. https ://doi.org/10.3109/13697137.2015.1124259.

76. Herbenick D, Reece M, Hensel D, Sanders S, Jozkowski K, Fortenberry JD. Association of lubricant use with women's sexual pleasure, sexual satisfaction, and genital symptoms: a prospective daily diary study. J Sex Med. 2011;8(1):202-12. https://doi.org/1 0.1111/j.1743-6109.2010.02067.x.

77. World Health Organization. Use and procurement of additional lubricants for male and female condoms: WHO/UNFPA/FHI360 Advisory Note. 2012. https://apps.who.int/iris/bitstream/handl e/10665/76580/WHO_RHR_12.33_eng.pdf?sequence=1\&isAll owed $=\mathrm{y}$.

78. Wysocki S, Kingsberg S, Krychman M. Management of vaginal atrophy: implications from the REVIVE Survey. Clin Med Insights Reprod Health. 2014;8:23-30. https://doi.org/10.4137/ cmrh.s 14498.

79. Chen J, Geng L, Song X, Li H, Giordan N, Liao Q. Evaluation of the efficacy and safety of hyaluronic acid vaginal gel to ease vaginal dryness: a multicenter, randomized, controlled, openlabel, parallel-group, clinical trial. J Sex Med. 2013;10(6):157584. https://doi.org/10.1111/jsm.12125.

80. Jokar A, Davari T, Asadi N, Ahmadi F, Foruhari S. Comparison of the hyaluronic acid vaginal cream and conjugated estrogen used in treatment of vaginal atrophy of menopause women: a randomized controlled clinical trial. Int J Community Based Nurs Midwifery. 2016;4(1):6-78.

81. Origoni M, Cimmino C, Carminati G, Iachini E, Stefani C, Girardelli S, et al. Postmenopausal vulvovaginal atrophy (VVA) is positively improved by topical hyaluronic acid application: a prospective, observational study. Eur Rev Med Pharmacol Sci. 2016;20(20):4190-5.

82. Mercier J, Morin M, Lemieux MC, Reichetzer B, Khalife S, Dumoulin C. Pelvic floor muscles training to reduce symptoms and signs of vulvovaginal atrophy: a case study. Menopause. 2016;23(7):816-20. https://doi.org/10.1097/gme.0000000000 000620 .

83. Arunkalaivanan A, Kaur H, Onuma O. Laser therapy as a treatment modality for genitourinary syndrome of menopause: a critical appraisal of evidence. Int Urogynecol J. 2017;28(5):681-5. https://doi.org/10.1007/s00192-017-3282-y.

84. Rabley A, O'Shea T, Terry R, Byun S, Louis Moy M. Laser therapy for genitourinary syndrome of menopause. Curr Urol Rep. 2018;19(10):83. https://doi.org/10.1007/s11934-018-0831-y.

85. US Food and Drug Administration. FDA warns against use of energy-based devices to perform vaginal 'rejuvenation' or vaginal cosmetic procedures: FDA Safety Communication. 2018. https:// www.fda.gov/MedicalDevices/Safety/AlertsandNotices/ucm61 5013.htm. Accessed 8 Mar 2019.

86. Gordon C, Gonzales S, Krychman ML. Rethinking the techno vagina: a case series of patient complications following vaginal laser treatment for atrophy. Menopause. 2019;26(4):423-7. https ://doi.org/10.1097/GME.0000000000001293.

87. Nappi RE, Kokot-Kierepa M. Women's voices in the menopause: results from an international survey on vaginal atrophy. Maturitas. 2010;67(3):233-8. https://doi.org/10.1016/j.matur itas.2010.08.001.

88. Shifren JL, Johannes CB, Monz BU, Russo PA, Bennett L, Rosen R. Help-seeking behavior of women with self-reported distressing sexual problems. J Womens Health (Larchmt). 2009;18(4):461-8. https://doi.org/10.1089/jwh.2008.1133.

89. Palma F, Xholli A, Cagnacci A. Management of vaginal atrophy: a real mess. Results from the AGATA study. Gynecol Endocrinol. 2017;33(9):702-7. https://doi.org/10.1080/09513590.2017.13090 18.

90. Kingsberg SA, Krychman M, Graham S, Bernick B, Mirkin S. The women's EMPOWER survey: identifying women's perceptions on vulvar and vaginal atrophy and its treatment. J Sex Med. 2017;14(3):413-24. https://doi.org/10.1016/j.jsxm.2017.01.010.

91. Krychman M, Graham S, Bernick B, Mirkin S, Kingsberg SA. The women's EMPOWER survey: women's knowledge and awareness of treatment options for vulvar and vaginal atrophy remains inadequate. J Sex Med. 2017;14(3):425-33. https://doi.org/10.1016/j. jsxm.2017.01.011.

92. Manson JE, Goldstein SR, Kagan R, Kaunitz AM, Liu JH, Pinkerton $\mathrm{JV}$, et al. Why the product labeling for low-dose vaginal estrogen should be changed. Menopause. 2014;21(9):911-6. https ://doi.org/10.1097/gme.0000000000000316.

93. Nappi RE, Palacios S, Panay N, Particco M, Krychman ML. Vulvar and vaginal atrophy in four European countries: evidence from the European REVIVE Survey. Climacteric. 2016;19(2):188-97. https://doi.org/10.3109/13697137.2015.1107039. 